\title{
PENGARUH KONSELING KELOMPOK TERHADAP SISWA YANG MENGALAMI STRES DALAM BELAJAR DI SMP NEGERI 1 BENGKULU TENGAH
}

\author{
Repi Handayani, Pudji Hartuti, Illawaty Sulian \\ Prodi Bimbingan dan Konseling Fakultas Keguruan dan Ilmu Pendidikan \\ Unversitas Bengkulu \\ handayanirepi@gmail.com, pudjihartuti@unib.ac.id, illawaty@unib.ac.id
}

\begin{abstract}
ABSTRAK
Penelitian ini bertujuan untuk mendeskripsikan pengaruh konseling kelompok terhadap siswa yang mengalami stres dalam belajar. Metode yang digunakan dalam penelitian ini adalah metode eksperimen dengan one group pre-test post-test design. Sampel penelitian sebanyak 8 orang siswa kelas VII.5 SMP Negeri 1 Bengkulu Tengah, yang diambil dengan teknik purposive sampling. Teknik pengumpulan data dalam penelitian ini menggunakan skala sikap stres belajar. Hasil penelitian menunjukkan ada pengaruh yang signifikan layanan konseling kelompok terhadap siswa yang mengalami stres belajar. Hal ini ditunjukkan dari hasil uji perbedaan sebelum dan sesudah diberikan layanan konseling kelompok terhadap tingkat stres dalam belajar siswa yaitu dengan menggunakan uji $\mathrm{z}$ yang hasilnya $\mathrm{z}=-2.524$ jadi $\mathrm{p}>0,05$. Dapat ditarik kesimpulan bahwa pelaksanaan layanan konseling kelompok berpengaruh terhadap siswa yang mengalami stres dalam belajar di SMP Negeri 1 Bengkulu Tengah.
\end{abstract}

Kata kunci : stres belajar, konseling kelompok

\section{THE INFLUENCE OF GROUP COUNSELINGSERVICE TO STUDENTS WHO EXPERIENCED STRESS IN LEARNING OF SMPN 1 BENGKULU TENGAH}

\begin{abstract}
This research aimed to describe the influence of group counseling the students who experience stress in learning. The method used in this research was experiment method by means of one group pre-test post-test design. The samples of research is 8 students of class VII.5 SMPN 1 Bengkulu Tengah, taken by applying purposive sampling technique. The data collection technique was by using the scale oflearning stress attitudes. The result showed that there was a significant influence of group counseling service the students who experience stress in learning. It was shown by the difference test result before and after given group counseling services to stress levels in student learning by using the ztest which resulted $z=-2.524$ so that $p>0.05$. It can be concluded that the implementation of group counseling services influence students who are experiencing stress in learning in SMPN 1 Bengkulu Tengah.
\end{abstract}

Keywords : Stress Learning, Group Counseling 


\section{Pendahuluan}

Purwanto (2007: 11) menjelaskan bahwa pendidikan adalah usaha orang dewasa dalam pergaulan dengan anak-anak untuk memimpin perkembangan jasmani dan rohaninya kearah kedewasaan. Tugas utama bagi seorang siswa adalah belajar. Sardiman (Rachma, 2014: 2) menyatakan bahwa belajar adalah perubahan perilaku dengan serangkaian kegiatan menulis, membaca, mengamati, mendengarkan, meniru dan sebagainya. Setiap siswa pastinya menginginkan hasil yang baik dalam belajar. Namun, dalam prosesnya muncul berbagai hambatan sehingga ada beberapa siswa tidak mampu mencapai hasil yang diinginkannya. Mustaqim (Rahmi, 2013: 67) menyatakan bahwa belajar lebih banyak berhubungan dengan aktivitas jiwa. Dengan kata lain, faktor-faktor psikis memang memiliki peran yang sangat menentukan dalam proses belajar dan hasilnya. Dalam keadaan stabil, perasaan sangat menolong individu dalam belajar. Namun, perasaan dengan intensitas sedemikian tinggi dapat menyebabkan seseorang kehilangan kontrol yang normal pada dirinya; misalnya takut, marah, stres, putus asa. Hal ini dapat menghambat proses dan prestasi belajar siswa yang mengalami stress belajar tersebut.

Shahmohammadi (Taufik dan Ifdil, 2013: 144) menjelaskan bahwa sebagian besar sumber stress pada siswa berasal dari masalah akademik. Stres pada anak pada bidang akademik muncul ketika harapan untuk meraih prestasi akademik meningkat, baik dari orang-tua, guru ataupun dari teman sebaya. Harapan tersebut seringkali tidak sesuai dengan kemampuan yang mereka miliki. Menurut Weidner (Rakhmawati, 2014: 73), Stres akademika dalah perasaan tertekan yang berhubungan dengan kegiatan pendidikan yang terjadi dalam masa pendidikan yang disebabkan oleh tuntutan yang tinggi timbul pada saat seseorang dalam masa pendidikan melebihi kemampuan yang dimiliki.

Dari tahun ke tahun Kementerian Pendidikan dan Kebudayaan menetapkan standar kelulusan yang selalu meningkat. Di samping itu, pemerintah daerah kabupaten dan kota juga menuntut dan kadang kala menekan pihak sekolah agar siswa dapat mencapai prestasi yang tinggi serta tingkat kelulusan siswa yang harus mendekati 100\% (Taufik dan Ifdil, 2013: 144). Tekanan yang dialami para siswa tentu berpengaruh pada prestasi belajar. Oleh karena itu, diperlukan psikolog yang dapat menangani masalah tersebut di setiap sekolah. Namun, karena keterbatasan waktu dan tenaga, setiap siswa belum tentu mendapatkan penanganan yang 
maksimal. Rainham (Taufik dan Ifdil, 2013: 144) menyatakan bahwa pada masa-masa sekolah menengah di satu sisi hal itu merupakan kesempatan untuk mendapatkan pengalaman yang sangat berharga, tetapi di sisi lain siswa dihadapkan adanya banyaknya tuntutan dan perubahan yang cepat. Akhirnya, hal itu dapat menyebabkan siswa mengalami stres.

Di Indonesia banyak ditemukan fenomena ketidakmampuan siswa untuk mengelola stres. Akibatnya hal itu berbuntut pada kejadian tragis, di antaranya melarikan diri dan di antaranya ada seorang siswa shock kemudian bunuh diri karena tidak lulus Ujian Nasional. Ada siswa perempuan di Bekasi yang malu karena nilai raportnya rendah kemudian menggantung diri, di Medan ada seorang gadis bunuh diri dengan cara meloncat dari plaza lantai 4 sebuah plaza karena tidak naik kelas (Taufik dan Ifdil, 2013: 144). Hasil Penelitian Depkes tahun1995 (Rachma, 2004: 2) di 13 kota besar di Indonesia menunjukkan 50\% siswa mengalami stres belajar. Hal ini ditandai dengan banyaknya sekolah yang memberikan berbagai macam pelajaran tanpa memperhatikan jeda waktu bagi siswa sehingga jika tidak sebanding dengan kemampuannya, maka dapat mengakibatkan dampak negati yang menghambat pencapaian tugas belajarnya.

Selain itu juga, perpindahan dari sekolah dasar kesatuan pendidikan lanjutan ini merupakan langkah yang cukup berarti dalam kehidupan anak, baik karena tambahan tuntutan belajar bagi siswa lebih berat, maupun karena siswa mengalami banyak perubahan dalam diri. Siswa berhadapan dengan sejumlah guru yang masing-masing memegang bidang studi tertentu. Hal ini menuntut siswa untuk menyesuaikan diri dengan beberapa gaya mengajar (Winkel dan Hastuti, 2004:141). Dari adanya berbagai tuntunan maupun beban belajar tersebut menyebabkan siswa merasa tertekan atau dengan kata lain mengalami stress belajar.

Berdasarkan hasil wawancara dengan guru BK SMP Negeri 1 Bengkulu Tengah pada tanggal 7 Desember 2017, diketahui bahwa masih banyak siswa yang mengalami kesulitan menyesuaikan diri terhadap tuntutan belajar yang ada di sekolah, terutamanya kelas VII yang baru mengikuti proses pendidikan di Sekolah Menengah Pertama. Selain itu, beban belajar dan tugas sekolah ataupun tugas rumah yang tergolong banyak dan sulit. Mereka kesulitan dalam memahami materi pelajaran serta sulit dalam mengikuti dan menyesuaiakan diri terhadap beberapa cara pengajaran guru yang berbeda-beda. Hal tersebut menyebabkan siswa kelas VII SMP Negeri 1 Bengkulu Tengah mudah merasa terbebani dan stres. 
Jika keadaan ini berlangsung lama dapat mengakibatkan dampak negatif bagi perkembangan diri individu yang mengalaminya. Maka dari itu perlu adanya tindak lanjut dalam mengatasi stres belajar yang dialami siswa, guna untuk pengembangan diri siswa yang lebih baik lagi yang sesuai dengan harapan dan tujuan yang diinginkan. Penanganan stres pada siswa dapat dilakukan dengan cara mengoptimalkan program bimbingan dan konseling.

Penelitian ini bertujuan untuk mendeskripsikan pengaruh implementasi layanan konseling kelompok dalam menurunkan stres belajar yang dialami siswa di kelas VII SMP Negeri 1 Bengkulu Tengah.

\section{Metode Penelitian}

Desain penelitian ini menggunakan desain deskripsi kuantitatif. Penelitian ini menggunakan metode eksperimen. Desain yang digunakan dalam penelitian ini adalah pre exsperimental design dengan jenis desain one group pre-test and post-test design. Dalam desain ini subjek diberikan perlakuan 2 kali pengukuran. Pengukuran pertama yang dilakukan adalah memberikan pre-test, kemudian dilakukan perlakuan dalam jangka waktu tertentu, yang selanjutnya diteruskan dengan pengukuran ke dua. Post-test pengukuran ke dua ini berupa posttest untuk melihat ada atau tidaknya perbedaan tingkat stresbelajar siswa antara sebelum dan sesudah diberikan perlakuan.

Pada penelitian ini yang menjadi populasi adalah seluruh siswa kelas VII ${ }^{5}$ SMP Negeri 1 Bengkulu Tengah yang berjumlah 27 orang, sedangkan sampel yang digunakan dalam penelitian ini berjumlah 8 orang siswa yang memperoleh skor stres belajar terendah dalam arti siswa yang mengalami stres belajar yang tinggi. Teknik pengambilan sampel dalam penelitian ini dengan menggunakan purposive sampling, yaitu sesuai dengan tujuan peneliti.

Dalam penelitian ini, dilakukan pengumpulan data dengan menggunakan angket dengan jenis angket skala likert dan dengan observasi. Sugiyono (2013: 142) menjelaskan bahwa angket merupakan teknik pengumpulan data yang dilakukan dengan cara memberi seperangkat pertanyaan atau pernyataan tertulis kepada responden untuk dijawabnya. Sarjono dan Julianita (2011: 6) menjelaskan bahwa skala Likert adalah skala yang digunakan untuk mengukur sikap, pendapat, dan persepsi seseorang atau sekelompok orang terhadap suatu kejadian atau keadaan sosial, dimana variabel yang akan diukur dijabarkan menjadi indikator variabel kemudian 
indikator tersebut dijadikan sebagai titik tolak untuk menyusun item-item pernyataan. Skala Likert mempunyai tingkatan dari sangat positif menjadi sangat negatif. Biasanya, menggunakan kata-kata berupa: sangat sesuai (SS), sesuai (S), tidak punya pendapat (TP), tidak sesuai (TS), dan sangat tidak sesuai (STS) yang diisi dengan memberi tanda checklist (Hadiwinarto, 2010: 122). Skala likert memiliki dua pernyataan, yaitu pernyataan positif (favorable) dan pernyataan negatif (unfavorable). Skala likert digunakan untuk mengukur stres belajar yang dialami siswa.

Pengumpulan data juga dilakukan dengan observasi. Nurkancana (1993: 35) menjelaskan bahwa observasi adalah suatu cara pengumpulan data dengan mengadakan pengamatan secara langsung terhadap suatu obyek dalam suatu periode tertentu dan mengadakan pencacatan secara sistematis tentang hal-hal tertentu yang diamati. Observasi yang dilakukan adalah dengan mengobservasi langsung kegiatan konseling kelompok yang dilakukan.

Sebelum angket diberikan kepada sampel penelitian angket tersebut di uji daya pembeda, validitas, dan reliabilitas. Sekaran (Sarjono dan Julianita, 2011: 35) menjelaskan bahwa validitas adalah bukti bahwa instrumen, teknik, atau proses yang digunakan untuk mengukur konsep benar-benar mengukur konsep yang dimaksudkan. Uji validitas bertujuan untuk mengukur valid tidaknya suatu item pernyataan. Berdasarkan hasil uji daya pembeda diperoleh hasil bahwa angket skala sikap stres belajar yang disebarkan ke 26 responden yang terdiri dari 46 item didapat 25 yang gugur dan 21 item pernyataan yang dinyatakan memenuhi kriteria uji daya pembeda. Hasil uji reliabilitas pada variabel diperoleh nilai Cronbach's Alpha $=0.857$.

Data yang diperoleh dari sampel penelitian kemudian dianalisis dengan uji hipotesis. Uji hipotesis ini mengunakan rumus uji-z, yang mana uji-z digunakan untuk mencari pengaruh konseling kelompok dalam menurunkan stres belajar yang dialami siswa. Untuk menguji hipotesis digunakan uji non parametrik dengan rumus Wilcoxon Signed Rank dengan menggunakan SPSS. 


\section{Hasil dan Pembahasan}

Tabel 1 Distribusi Frekuensi Pre-test

\begin{tabular}{lcc}
\hline \multicolumn{1}{c}{ Interval skor } & Frekuensi & Kategori \\
\hline $71>$ & 4 & Sangat tinggi \\
\hline $63-70$ & 3 & Tinggi \\
\hline $59-62$ & 1 & Sedang \\
\hline $55-58$ & - & Rendah \\
\hline$<54$ & - & Sangat rendah \\
\hline Total & 8 & - \\
\hline
\end{tabular}

Hasil pengambilan data awal (pre-test) kategori sebagaimana Tabel 1 terlihat bahwa siswa yang mendapatkan skor frekuensi sangat tinggi sebanyak 4 orang yang persentasenya sebesar $50 \%$, siswa yang mendapatkan skor frekuensi tinggi sebanyak 3 orang yang persentasenya 37\%, dan siswa yang mendapatkan skor frekuensi sedang sebanyak 1 orang yang persentasenya $13 \%$. Dari data pada tabel 1 dapat disimpulkan bahwa siswa yang dikategorikan mengalami stres belajar sangat tinggi sebanyak 4 orang, siswa yang dikategorikan mengalami stres belajar yang tinggi sebanyak 3 orang, dan siswa yang dikategorikan mengalami stres belajar yang sedang sebanyak 1 orang.

Tabel 2 Distribusi Frekuensi Post-test

\begin{tabular}{lcc}
\hline \multicolumn{1}{c}{ Interval skor } & Frekuensi & Kategori \\
\hline $71>$ & - & Sangat tinggi \\
\hline $63-70$ & - & Tinggi \\
\hline $59-62$ & - & Sedang \\
\hline $55-58$ & - & Rendah \\
\hline$<54$ & 8 & Sangat rendah \\
\hline Total & 8 & - \\
\hline
\end{tabular}

Pada tabel 2 dapat dilihat ada penurunan skor yang semula berada pada kategori sangat tinggi, tinggi, dan sedang. Kemudian semua siswa berada pada kategori sangat rendah yang persentasenya sebesar $100 \%$ dengan interval $(<54)$. Berdasarkan penurunan skor tersebut maka dapat disimpulkan bahwa adanya penurunan stres belajar yang dialami siswa. 
Tabel 3 Penurunan Skor

\begin{tabular}{ccccccc}
\hline No & $\begin{array}{c}\text { Nama } \\
\text { siswa }\end{array}$ & $\begin{array}{c}\text { Skorpr } \\
\text { e-test }\end{array}$ & Kategori & $\begin{array}{c}\text { Skorpos } \\
\text { t-test }\end{array}$ & Kategori & $\begin{array}{c}\text { Penurunan } \\
\text { skor }\end{array}$ \\
\hline $\mathbf{1}$ & AB & 64 & Tinggi & 45 & Sangatrendah & 10 \\
\hline $\mathbf{2}$ & CD & 70 & Tinggi & 49 & Sangat rendah & 21 \\
\hline $\mathbf{3}$ & EF & 72 & Sangattinggi & 46 & Sangat rendah & 26 \\
\hline $\mathbf{4}$ & GH & 62 & Sedang & 47 & Sangat rendah & 15 \\
\hline $\mathbf{5}$ & IJ & 67 & Tinggi & 45 & Sangat rendah & 22 \\
\hline $\mathbf{6}$ & KL & 76 & Sangattinggi & 50 & Sangat rendah & 26 \\
\hline $\mathbf{7}$ & MN & 71 & Sangattinggi & 46 & Sangat rendah & 25 \\
\hline $\mathbf{8}$ & OP & 71 & Sangattinggi & 44 & Sangat rendah & 27 \\
\hline Jumlah & 553 & - & 372 & - & 181 \\
\hline Rata-rata & 69.125 & - & 46.5 & - & 22.625 \\
\hline
\end{tabular}

Dari tabel 3 menunjukkan bahwa ada perbedaan yang signifikan tingkat stres belajar siswa sebelum dan sesudah diberikan layanan konseling kelompok. Data pre-test menunjukkan bahwa skor rata-rata 69.125 termasuk dalam kategori tinggi, yang berarti stres belajar yang dialami siswa di SMPN 1 Bengkulu Tengah masih tergolong tinggi, khususnya kelas VII.5 SMPN 1 Bengkulu Tengah. Setelah diberikan layanan konseling kelompok, stres belajar siswa menjadi lebih baik dibandingkan sebelum diberikan layanan konseling kelompok. Hal tersebut terbukti dari hasil post-test yang menurun menjadi rata-rata 46.5 termasuk dalam kategori sangat rendah.

Tabel 4 Reliability Statistics

\begin{tabular}{ll}
\hline Cronbach's Alpha & N of Items \\
\hline .857 & 21 \\
\hline
\end{tabular}

Berdasarkan tabel 4 menunjukkan bahwa nilai $\mathrm{Z}$ yaitu -2.524 dengan signifikan 0,012 yang berarti nilai signifikan $0,012<0,05$ sehingga $\mathrm{H}_{\mathrm{o}}$ ditolak dan $\mathrm{H}_{\mathrm{a}}$ diterima. Berdasarkan hasil uji hipotesis yang menggunakan rumus uji Z dapat disimpulkan bahwa konseling kelompok dapat menurunkan stres belajar siswa kelas VII di SMP Negeri 1 Bengkulu Tengah.

Belajar merupakan salah satu kewajiban dari seorang siswa. Belajar seharusnya dilakukan bukan hanya di sekolah saja tetapi juga di lakukan di rumah agar hasil yang didapat bisa 
memuaskan seperti yang diharapkan. Namun, banyak dari siswa yang tidak mampu memenuhi kewajiban tersebut sepenuhnya. Banyak dari siswa yang mengalami beberapa masalah dan kesulitan dalam mencapai hasil belajar yang baik sehingga semakin banyak kesulitan dan hambatan yang muncul maka akan mengakibatkan siswa mengalami stres belajar yang tinggi. Stres belajar adalah suatu tekanan yang dirasakan oleh individu karena adanya kesenjangan antara tuntutan belajar dengan kemampuan yang dimilikinya sehingga menyebabkan individu tersebut mudah bosan, jenuh, tidak fokus dan menghindar dari kegiatan yang berhubungan dengan belajar. Sedangkan Campbell \& Svenso (Aryani, 2016: 25) menjelaskan bahwa stres belajar adalah tekanan-tekanan yang dihadapi anak berkaitan dengan tugas-tugas sekolah yang dipersepsikan secara negatif, dan berdampak pada kesehatan fisik, psikis, dan performansi belajarnya.

Dari hasil pengamatan beberapa penyebab siswa mengalami stres belajar adalah banyaknya tugas sekolah yang harus diselesaikan oleh siswa ketika di rumah sedangkan tidak semua siswa memiliki waktu luang yang banyak. Ada sebagian siswa aktivitasnya bukan hanya belajar saja tetapi juga memiliki aktivitas-aktivitas yang lain seperti mengikuti ekstrakulikuler yang mana ekstrakulikuler tersebut latihannya ketika sepulang sekolah yang membuat siswa pulang sore. Selain itu ada juga banyak siswa yang tidak menyukai dan tidak sesuai dengan guru yang mengajar mata pelajaran tertentu, baik itu terhadap cara guru tersebut mengajar atau juga terhadap sifat guru yang mengajar tersebut. Hal itu membuat siswa jadi malas untuk belajar dan malas untuk memahami materi. Hal tersebut tentunya akan berdampak negatif terhadap siswa tersebut. Siswa menjadi malas mengikuti pembelajaran mata pelajaran tersebut dantidak mengerti materinya sedikitpun sehingga ketika ada ulangan siswa menjadi pusing dan akhirnya mengalami stres belajar pada mata pelajaran tersebut.

Berdasarkan uji $\mathrm{Z}$ yang telah dilakukan diperoleh sig. (2-tailed) $\mathrm{p}=0,012(\mathrm{p}<0,05$ sehingga $\mathrm{H}_{\mathrm{o}}$ ditolak dan $\mathrm{H}_{\mathrm{a}}$ diterima. Maka ada perbedaan terhadap stres belajar yang dialami siswa kelas VII SMP Negeri 1 Bengkulu Tengah sebelum dan sesudah diberikan layanan konseling kelompok, artinya layanan konseling kelompok efektif menurunkan stres belajar yang dialami siswa. Dengan demikian disimpulkan bahwa stres belajar siswa sebelum dan sesudah mendapatkan konseling kelompok adalah berbeda, dan mengalami penurunan yang signifikan. 
Konseling kelompok merupakan upaya pembimbing atau konselor dalam membantu memecahkan masalah-masalah pribadi yang dialami oleh masing-masing anggota kelompok melalui kegiatan kelompok agar tercapai perkembangannya secara optimal (Tohirin, 2007: 172). Melalui kegiatan layanan konseling kelompok siswa mendapatkan kesempatan untuk menceritakan semua masalah-masalah mereka secara bergiliran yang dibahas secara bersamasama untuk mencari solusi pengentasannya.Siswa juga diberikan kesempatan menyampaikan perasaan dan harapannya pada masa mendatang.

\section{Kesimpulan}

Ada pengaruh dari treatment (perlakuan) layanan konseling kelompok untuk menurunkan stress belajar yang dialami siswa. Hal ini dapat dibuktikan dari hasil analisis data yang menunjukkan bahwa Ho ditolak dan Ha diterima. Hal ini berarti berarti layanan konseling kelompok dapat menurunkan stress belajar yang dialami siswa kelas VII SMP Negeri 1 Bengkulu Tengah.

\section{Daftar Pustaka}

Aryani, F. (2016). Stress Belajar. Makassar: Edukasi Mitra Grafika.

Hadiwinarto. (2010). Penajaman Penilaian Karakter dan Budi Pekerti. Bengkulu: Bahanapro.

Nurkancana, W. (1993).Pemahaman Individu. Surabaya: Usaha Nasional.

Purwanto, M.N. (2007). Ilmu Pendidikan Teoritis dan Praktis. Bandung: Remaja Rosdakarya.

Rachma, N.F. (2014). Penerapan Konseling Kelompok dengan Menggunakan Strategi Coping untuk Mengurangi Stres Belajar Siswa Kelas X SMA Negeri 1 Tuban. Jurnal BK Universitas Negeri Surabaya, 04 (03), 1-10.

Rahmi, N. (2013). Hubungan Tingkat Stres dengan Prestasi Belajar Mahasiswa Tingkat II Prodi D-III Kebidanan Banda Aceh Jurusan Kebidanan Poltekkes Kemenkes NAD TA.2011/2012. Jurnal Ilmiah STIKes U'Budiyah, 2(1), 66-76.

Rakhmawati, I., Farida, P., \& Nurhalimah. (2014). Sumber Stres Akademik dan Pengaruhnya Terhadap Tingkat Stres Mahasiswa Keperawatan DKI Jakarta. Jurnal Keperawatan, 2 (3), 72-84.

Sarjono, H., \& Julianita, W. (2011).SPSS vs LISREL Sebuah Pengantar, Aplikasi untuk Riset. Jakarta: Salemba Empat. 
Sugiyono. (2013). Metode Peneitian Kuantitatif, Kualitatif, dan R \& D. Bandung: Alfabeta.

Taufik \& Ifdil.(2013). Kondisi Stres Akademik Siswa SMA Negeri di Kota Padang. Jurnal Konseling dan Pendidikan, 1 (2), 143-150.

Tohirin. (2007). Bimbingan dan Konseling di Sekolah dan Madrasah (Berbasis Integrasi). Jakarta: Rajagrafindo Persada.

Winkel, W.S \& Hartuti, S. (2004). Bimbingan dan Konseling di Institusi Pendidikan. Yogyakarta: Media Abadi. 